\title{
Dietary Approaches to Stop Hypertension (DASH) diets and breast cancer among women: a case control study
}

\author{
Zeinab Heidari ${ }^{1 \dagger}$, Elahe Mohammadi ${ }^{\dagger \dagger}$, Vahideh Aghamohammadi², Saba Jalali', Arezoo Rezazadeh', \\ Fatemeh Sedaghat ${ }^{3 *}$, Mojan Assadi ${ }^{4}$ and Bahram Rashidkhani ${ }^{1}$
}

\begin{abstract}
Background: Studying entire dietary patterns is a promising alternative approach to overcome limitations of the single food or nutrient approach. We evaluated the relationship between the scores of 4 established Dietary Approaches to Stop Hypertension (DASH) diet indexes and breast cancer risk among Iranian women.

Methods: This case-control study was carried out on 408 eligible women (136 cases and 272 hospital-based controls). A validated 168 item semi-quantitative food frequency questionnaire was used for assessing usual dietary intakes. DASH index scores were generated based on predefined algorithms for each of the 4 previously described indexes (Dixon's, Mellen's, Fung's and Günther's DASH diet index). Unconditional logistic regression analysis was performed to estimate odds ratio (OR) and 95\% confidence intervals (Cls) for score categories or quintiles of DASH diet indexes and breast cancer risk in multivariate adjusted models.

Results: Women in the highest categories of the Mellen's and Günther's scores had lower odds of breast cancer than those in the lowest quintiles (Mellen's OR:0.50; 95\% Cl:0.62-0.97; P-trend:0.02; Günther's OR:0.48; 95\% Cl:0.250.93; P-trend:0.05). However, no significant associations were found between Dixon's and Fung's DASH score and breast cancer risk. Modification by menopausal status revealed that breast cancer risk was only reduced in postmenopausal women with higher scores on Mellen's index (OR:0.24; 95\% Cl:0.08-0.68; P-trend:0.04).
\end{abstract}

Conclusion: A greater adherence to 2 of the 4 DASH indexes (Mellen's and Günther's indexes) was associated with decreased risk of breast cancer.

Keywords: Breast cancer, Diet, DASH diet, Case-control

\section{Background}

Breast cancer, the most prevalent cancer in women, is a major public health problem worldwide [1]. Breast cancer is a leading cause of death among female both in developed and developing countries [2]. In Iran, breast cancer

\footnotetext{
* Correspondence: sedaqat_fateme@yahoo.com

'Zeinab Heidari and Elahe Mohammadi contributed equally to this work. ${ }^{3}$ Department of Basic Medical Sciences, Faculty of Nutrition Sciences and Food Technology, National Nutrition and Food Technology Research Institute, ShahidBeheshti University of Medical Sciences, No 46, Hafezi Street, Farahzadi Boulevard, Sharak Ghods, P.O. Box: 1981619573, Tehran, Iran Full list of author information is available at the end of the article
}

ranks first among diagnosed malignancies in women, comprising $24.4 \%$ of all cancers with the age-standardized incidence rates of 23.1 per 100,000 , and is the fifth most common causes of death due to cancers [3].

Among environmental risk factors of breast cancer, diet has been considered as an important modifiable exposure [4]. However, epidemiological studies have reported conflicting results regarding the association between food intake and breast cancer risk [5, 6]. On the other hand, most of these studies have traditionally focused on the effects of individual foods and nutrients on cancer risk [6-8].

(C) The Author(s). 2020 Open Access This article is licensed under a Creative Commons Attribution 4.0 International License, which permits use, sharing, adaptation, distribution and reproduction in any medium or format, as long as you give appropriate credit to the original author(s) and the source, provide a link to the Creative Commons licence, and indicate if changes were made. The images or other third party material in this article are included in the article's Creative Commons licence, unless indicated otherwise in a credit line to the material. If material is not included in the article's Creative Commons licence and your intended use is not permitted by statutory regulation or exceeds the permitted use, you will need to obtain permission directly from the copyright holder. To view a copy of this licence, visit http://creativecommons.org/licenses/by/4.0/ The Creative Commons Public Domain Dedication waiver (http://creativecommons.org/publicdomain/zero/1.0/) applies to the data made available in this article, unless otherwise stated in a credit line to the data. 
Although, some potential biological mechanisms that underlie observed associations can be identified, "single nutrient" approach may not detect small effects of single dietary components and can be limited by the multicollinearity of dietary intake variables $[5,7,8]$. Therefore, studying entire dietary patterns is a promising alternative approach to overcome limitations of the single food or nutrient approach, account for the combined effects of and synergy between single dietary components $[5,7,8]$ and provides useful information for suggesting guidelines and public health recommendations [7]. The Dietary Approaches to Stop Hypertension (DASH) which emphasizes fruits and vegetables, plant proteins, moderate amounts of low-fat dairy products, and low amounts of sweets and sodium, is a healthy eating pattern recommended for the general public by the United States Department of Agriculture $[7,9,10]$. Though this dietary approach was at first suggested to reduce hypertension and cardiovascular disease risk, several previous studies reported the inverse association between DASH diet score and colorectal cancer $[7,11,12]$. It seems that DASH diet might be effective for cancer prevention, especially because some of its characteristics, like high fruit and vegetable consumption and low meat intake, have been implicated in the etiology of cancer [7, 10]. While several prospective [13-17] and case-control [18-22] studies have considered exploratory dietary patterns and breast cancer risk, few studies have examined the associations between DASH scores and breast cancer [5, 10, 23]. A prospective cohort study showed that a high DASH score reduced the risk of estrogen receptor negative (ER-) breast cancer [10] and another case-control study indicated an inverse association between adherence to the DASH eating plan and odds of breast cancer in Iranian women [23]. On the other hand, the association between habitual intake of the DASH dietary pattern and breast cancer has not been adequately investigated in the Middle East, where the dietary intakes are greatly different from those in Western countries. Moreover, these limited studies have equivalently adopted the operationalized approach proposed by Fung et al. to calculate the DASH index [12]. Therefore, the purpose of the current study was to compare scores of 4 established DASH diet indexes [11, 24-26] and evaluate their relations to breast cancer risk among Iranian women.

\section{Methods}

\section{Subjects}

This hospital-based case-control study was carried out on women aged $\geq 30$ years who were admitted to Shohadaye Tajrish and Imam Hossein hospitals in Tehran, Iran from September 2015 to February 2016. Only patients with histopathologically proven breast cancer (and no history of other cancers) were designated as breast cancer patients. Eligible cases were all incident cases of breast cancer in past 6 months who did not undergo any cancer treatments at the time of interview. Exclusion criteria for cases were history of hormone replacement therapy, being pregnant or lactating and having special dietary habits such as vegetarian.

The control group was then selected randomly among women referred to the same hospitals for a broad spectrum of non-neoplastic diseases not related to known or suspected risk factors for breast cancer and their eating habits. The exclusion criteria for controls were history of physician-diagnosed cancer in any site, HRT and benign breast disease, pregnancy or breast-feeding, and having special dietary habits. Two controls were enrolled for each case and matched for diagnosis hospital, menopausal status and age ( \pm 5 years). The participation rate was $95 \%$ for cases and $89 \%$ for control and $92 \%$ for all of them. Of the 408 eligible subjects participated in this study, a total of 401 subjects (134 cases and 267 controls) were included in the final analysis. Five controls and 2 cases were excluded from study because their daily energy intakes were either $>3$ or $<3 \mathrm{SD}$ from the mean. The ethics committee of the National $\mathrm{Nu}$ trition and Food Technology Research Institute of Shahid Beheshti University of Medical Science approved the study protocol and a written informed consent was obtained from all volunteers before enrolment in the study.

\section{Data collection}

Questionnaire data regarding socio-demographic variables, history of cancer and other diseases, family history of cancer, reproductive history, HRT and vitamin D supplement use, and current or past smoking behavior were collected from participants at baseline. Information on the subject's activity level was gathered using a valid physical activity questionnaire [27] and was then quantified in form of metabolic equivalent hour/day (METs-h/ d). This method has been described in detail elsewhere $[27,28]$. Weight was measured using digital scale (Seca, Germany) while the subjects were minimally clothed without shoes and recorded to the nearest $100 \mathrm{~g}$. Height was measured via a wall mounted stadiometer (Seca, Germany) with $2 \mathrm{~mm}$ precision, while the participants wearing no shoes. The ratio of weight (in $\mathrm{kg}$ ) to square of height (in meter) was used to determine the individual's body mass index (BMI).

\section{Dietary assessment}

We used a validated 168 item semi-quantitative food frequency questionnaire (FFQ) with multiple choice frequency response options for assessing usual dietary intakes of all participants. Reproducibility and relative validity of this FFQ in evaluating major dietary patterns and food and nutrient intake among Iranian adults have already been demonstrated [29]. Subjects were asked to provide the frequency of consumption of certain portions 
of each food on a daily, weekly, monthly or yearly basis throughout the preceding year before cancer diagnosis (for cases) or hospital admission (for controls). By using household measures, the portion sizes for each food item were converted to grams. Specified portion size, dish composition, and the average of reported frequency (e.g., divided by 30 if once a month) was taken into consideration to calculate daily value for each food item. To calculate the FFQ nutrient intakes, the modified Nutritionist IV software was used. The modification was done to include the Iranian foods in the original USDA food composition table embedded in the software.

\section{The DASH score}

Computation of the DASH scores has previously been described in detail [7]. DASH index scores were generated based on the separate indexes defined by Mellen, Fung, Dixon, and Günther [11, 24-26]. Table 1 shows scoring standards and points for use in all these indexes. Dixon's DASH diet index includes 8 food groups and one nutrient (total fruits, total vegetables, whole grains, total dairy products, nuts/seeds/legumes, meat/meat equivalent, added sugar, saturated fat and alcohol). One point is assigned to each one. The total score is the sum of the individual 9 components scores, which ranges 0 to 9 scores. However, in our study alcohol components were removed from the Dixon's DASH score due to religious practices. The recommended cut-off values for energy intakes were 1600 and $2000 \mathrm{kcal} / \mathrm{d}$ for women and men, respectively.

Mellen et al. [26] designed a totally nutrient-based DASH diet index (Table 1). Greater adherence to the Mellen's DASH diet index was associated with higher intakes of potassium, protein, fiber, magnesium, and calcium, and lower intakes of cholesterol, sodium, total fat, and saturated fat. The daily nutrient goal was set to a $2100 \mathrm{kcal} / \mathrm{d}$ diet, regardless of subject's gender. One point assigned to those who meet the goal for each component, those who meet an intermediate goal receive 0.5 point, and 0 points was attributed to those who do not meet either of the two goals. The total score ranges from 0 to $9[7,26]$.

Fung's index is the traditional DASH diet scoring system and includes 8 components highlighted or minimized in the DASH diet: high intakes of whole grains, fruits (includes fruit juice), vegetables (excludes potatoes), low-fat dairy products, and nuts and legumes, as well as low intakes red and processed meats, sweetened beverages, and sodium. The scoring system is based on quintile categories of eating the mentioned food items. For recommended components, those in the lowest quintile of intake receive 1 point and those in the highest quintile receive 5 points. In contrast, for components for which lower intakes are favorable, those in the highest and the lowest quintile of intake receives 1 and 5 points, respectively. Component scores were then summed up to construct an overall adherence to DASH score, ranging from 8 to 40 .

A more complex food-based DASH diet index has been defined by Günter et al. [25]. This index relies on 10 components to evaluate the individual's compliance to the DASH diet plan. In accordance to their scales, these components are divided as follows:

- Six components on a 10-point scale, which include: (i) fruits and fruit juice, (ii) vegetables and potato, (iii) meat, poultry, fish and eggs, (iv) nuts, seeds and legumes, (v) fats and oils, and (vi) sweets.

- Four components with a 5-point scale, including: (i) total dairy, (ii) low-fat dairy, (iii) whole grains, and (iv) high-fiber grains.

Recommendations for 4 various energy intakes including $1600,2000,2300$, and $3100 \mathrm{kcal} / \mathrm{d}$ are the basis of target intakes for each component that accounts for activity level, sex, and age defined by Dietary Reference Intakes (25). The ultimate DASH index is calculated by adding up the acquired points, and it yields a value in the range of 0 to 80 .

\section{Statistical analysis}

The statistical analyses were carried out in the SPSS commercial package, version 18 (SPSS Inc., Chicago, IL, USA). All the significance tests were performed with the confidence interval of, at least, 95\% (corresponding to a $p$-value $\leq 0.05)$. In order to conduct statistical analyses on all the above-mentioned DASH scores (Mellen's, Fung's, and Günther's) in this study, they were expressed as distribution-based indexes and the lowest quintile was considered as the referent category. Given the fact that Dixon's DASH index is a whole numbers 9-point scale with a limited range of values, score categories $\leq 1$ (referent category), 2, 3, and $\geq 4$ were selected. Unconditional logistic regression analysis was performed to estimate odds ratio (OR) and their corresponding 95\% confidence intervals for score categories or quintiles of DASH diet indexes and breast cancer risk in multivariate adjusted models. The possibilities of effect modification by menopausal status were considered by additional models. Moreover, complementary analyses were performed to examine whether individual components of DASH index are independently associated with the risk of breast cancer. All multivariable models were adjusted for the following covariates: age (y), BMI (in $\mathrm{kg} / \mathrm{m}^{2}$ ), physical activity, smoking, total energy intake $(\mathrm{kcal} / \mathrm{d})$, vitamin $\mathrm{D}$ supplement use, age at first live birth, and family history of cancer. Furthermore, in order to compare total scores on the 4 indexes, Spearman's correlation coefficients were calculated. 
Table 1 Standards for maximum scores on 4 DASH diet indexes

\begin{tabular}{|c|c|c|c|c|}
\hline \multicolumn{5}{|l|}{ Standards for maximum score } \\
\hline & $\begin{array}{l}\text { Dixon's DASH index } \\
\text { In women } \\
\text { Sex-specific (women) }\end{array}$ & Mellen's DASH index ${ }^{\mathrm{b}}$ & $\begin{array}{l}\text { Fung's DASH index } \\
\text { Sex-specific (women) }\end{array}$ & $\begin{array}{l}\text { Günther's DASH index }{ }^{\text {d,e, }} \\
\text { Based on age, sex and activity }\end{array}$ \\
\hline \multicolumn{5}{|c|}{ Dietary components for which greater intakes receive higher score } \\
\hline Total fruit & $\geq 4$ servings $/ \mathrm{d}^{f}$ & & Fifth quintile & $\geq 4$ servings $/ \mathrm{d}^{\mathrm{f}}$ \\
\hline Total vegetables & $\geq 3$ servings $/ d^{f, g}$ & & & $\geq 4$ servings $/ \mathrm{d}^{\mathrm{f}}$ \\
\hline Vegetables without potatoes & & & Fifth quintile & \\
\hline Total grains & & & & $\geq 6$ servings $/ \mathrm{d}^{f}$ \\
\hline Whole grains & $\geq 4$ servings $/ d^{f, g}$ & & Fifth quintile & \\
\hline High-fiber grains & & & & $\geq 50 \%$ of total grain servings $/ d^{f, h}$ \\
\hline Total dairy products & $\geq 2$ servings/d $\mathrm{d}^{f}$ & & & $\geq 2$ servings $/ d^{6}$ \\
\hline Low-fat dairy products & & & Fifth quintile & $\geq 75 \%$ of total dairy servings/d,h \\
\hline Nuts, seeds, legumes & $\geq 3$ servings $/ d^{f}$ & & Fifth quintile & $\geq 4$ servings $/ w^{f}{ }^{f}$ \\
\hline Protein & & $\geq 18 \%$ of total daily kcal & & \\
\hline Fiber & & $\geq 14.8 \mathrm{~g} / 1000 \mathrm{kcal}$ per day & & \\
\hline Magnesium & & $\geq 238 \mathrm{mg} / 1000 \mathrm{kcal}$ per day & & \\
\hline Calcium & & $\geq 590 \mathrm{mg} / 1000 \mathrm{kcal}$ per day & & \\
\hline Potassium & & $\geq 2238 \mathrm{mg} / 1000 \mathrm{kcal}$ per day & & \\
\hline \multicolumn{5}{|c|}{ Dietary components for which lower intakes receive higher scores } \\
\hline Meat/meat equivalents & $<6 \mathrm{oz} .(170 \mathrm{~g}) / \mathrm{d}^{\mathrm{f}}$ & & & \\
\hline Meat, poultry, fish, eggs & & & & $\leq 2$ servings $/ \mathrm{d}^{\mathrm{f}}$ \\
\hline Red and processed meat & & & First quintile & \\
\hline Sugar-sweetened beverages & & & First quintile & \\
\hline Sweets & & & & $\leq 5$ servings/wk $k^{f}$ \\
\hline Fats, oils & & & & $\leq 3$ servings $/ \mathrm{d}^{\mathrm{f}}$ \\
\hline Added sugar & $\leq 3 \%$ of total daily kcal & & & \\
\hline Total fat & & $27 \%$ of total daily kcal & & \\
\hline Saturated fat & $\leq 5 \%$ of total daily $\mathrm{kcal}$ & $\leq 6 \%$ of total daily kcal & & \\
\hline Cholesterol & & $\leq 71.4 \mathrm{mg} / 1000 \mathrm{kcal}$ per day & & \\
\hline Sodium & & $\leq 1143 \mathrm{mg} / 1000 \mathrm{kcal}$ per day & 1st quintile & \\
\hline Total score (points) & $0-8$ & $0-9$ & $8-40$ & $0-80$ \\
\hline
\end{tabular}

${ }^{\mathrm{a}}$ Subjects receive 0 points for not meeting and 1 points for meeting the recommendation

${ }^{\mathrm{b}}$ Subjects receive 1 points for meeting a target, 0.5 points for meeting an intermediate target, and 0 points for meeting neither target

${ }^{c}$ For recommended components, the highest quintile receives 5 points, and the lowest quintile receives 1 point; for components for which lower intakes are

desirable, the lowest quintile of intake receives 5 points and the highest quintile of intake receives 1 point

${ }^{\mathrm{d}}$ Standards are based on recommendations for a $2000 \mathrm{cal}$ diet; different standards are available for 3 other energy intakes (1600, 2300 , and $\left.3100 \mathrm{kcal}\right)$ according to sex, age and levels of physical activity

eComponents are scored from 0 to 10 , except for total dairy, low-fat dairy, whole grains, and high-fiber grains which are scored from 0 to 5

fValues are based on the Pyramid Servings database

${ }^{9} \mathrm{~A}$ total of 4 servings were based on the Dietary Guidelines recommendation for most grains to be whole, that Dixon et al. defined as $67 \%$ [11]

hIf servings of total grains or total dairy were 0 , components of high-fiber grains or low-fat dairy products would receive 0 points

\section{Results}

Table 2 shows the baseline characteristics according to categories or quintiles of total DASH scores for all indexes. Women in control group with high scores on Mellen's and Dixon's indexes tended to start their menarche at a slightly older age. Also, women in control group with high scores on Mellen's index were older. In both case and control groups, women with higher scores on all indexes had higher energy intake, the only exception was with the Mellen's index which is an energy adjusted model. Women in control group with high scores on Fung's index were more physically active.

Table 3 presents the correlations between total scores for all DASH indexes. Correlation coefficients ranged from 0.07 to0.69. The highest correlation was observed between Fung's and Dixon's indexes $(r=0.69)$, while the 
Table 2 Characteristics of subjects according to category or quintiles of 4 DASH diet index scores

\begin{tabular}{|c|c|c|c|c|c|c|c|c|c|c|c|c|}
\hline & \multicolumn{3}{|c|}{ Dixon's DASH index ${ }^{a}$} & \multicolumn{3}{|c|}{ Mellen's DASH index } & \multicolumn{3}{|c|}{ Fung's DASH index } & \multicolumn{3}{|c|}{ Günther'sDASH index } \\
\hline & $<1$ point & $\geq 4$ points & $P$-value & Quintile 1 & Quintile 5 & $P$-value & Quintile 1 & Quintile 5 & $P$-value & Quintile 1 & Quintile 5 & $P$-value \\
\hline \multicolumn{13}{|l|}{ Median score } \\
\hline Cases & 1 & 2 & & 1 & 4 & & 17 & 31 & & 53 & 70 & \\
\hline Control & 1 & 2 & & 1 & 4 & & 19 & 31 & & 54 & 70 & \\
\hline \multicolumn{13}{|l|}{ Number } \\
\hline Cases & 61 & 17 & & 39 & 24 & & 44 & 26 & & 41 & 30 & \\
\hline Control & 89 & 38 & & 51 & 56 & & 53 & 46 & & 53 & 53 & \\
\hline \multicolumn{13}{|l|}{ Age } \\
\hline Case & $48.0 \pm 10.0^{b}$ & $\begin{array}{l}51.0 \pm \\
10.0\end{array}$ & 0.38 & $\begin{array}{l}48.0 \pm \\
11.0\end{array}$ & $\begin{array}{l}49.0 \pm \\
10.0\end{array}$ & 0.31 & $47.0 \pm 10.0$ & $50.0 \pm 9.0$ & 0.20 & $46.0 \pm 10.0$ & $50.0 \pm 9.0$ & 0.20 \\
\hline Control & $47.0 \pm 10.0$ & $\begin{array}{l}49.0 \pm \\
10.0\end{array}$ & 0.20 & $43.0 \pm 7.0$ & $\begin{array}{l}49.0 \pm \\
11.0\end{array}$ & 0.03 & $47.0 \pm 9.0$ & $51.0 \pm 8.0$ & 0.01 & $49.0 \pm 10.0$ & $\begin{array}{l}45.0 \pm \\
12.0\end{array}$ & 0.25 \\
\hline \multicolumn{13}{|l|}{ Weight } \\
\hline Case & $\begin{array}{l}73.0(20 . \\
0)^{c}\end{array}$ & $\begin{array}{l}74.0 \\
(15.0)\end{array}$ & 0.82 & $\begin{array}{l}75.0 \\
(22.0)\end{array}$ & $\begin{array}{l}72.0 \\
(18.0)\end{array}$ & 0.92 & $73.0(16.0)$ & $\begin{array}{l}75.00 \\
(14.0)\end{array}$ & 0.25 & $76.0(26.0)$ & $\begin{array}{l}72.0 \\
(22.0)\end{array}$ & 0.82 \\
\hline control & $72.0(20.0)$ & $\begin{array}{l}68.0 \\
(20.0)\end{array}$ & 0.56 & $\begin{array}{l}68.0 \\
(12.0)\end{array}$ & $\begin{array}{l}75.0 \\
(19.0)\end{array}$ & 0.03 & $72.0(13.0)$ & $\begin{array}{l}71.00 \\
(10.0)\end{array}$ & 0.99 & $72.0(19.0)$ & $\begin{array}{l}70.00 \\
(23.0)\end{array}$ & 0.47 \\
\hline \multicolumn{13}{|l|}{ Height } \\
\hline Case & $158.0(7.0)^{c}$ & $\begin{array}{l}160.0 \\
(4.0)\end{array}$ & 0.32 & $158.0(10)$ & $\begin{array}{l}155.0 \\
(9.0)\end{array}$ & 0.43 & $158.0(4.0)$ & $\begin{array}{l}157.0 \\
(5.0)\end{array}$ & 0.58 & $159.0(7.0)$ & $\begin{array}{l}157.0 \\
(9.0)\end{array}$ & 0.13 \\
\hline Control & $159.0(8.0)$ & $\begin{array}{l}158.0 \\
(5.0)\end{array}$ & 0.72 & $\begin{array}{l}157.0 \\
(6.0)\end{array}$ & $\begin{array}{l}160.0 \\
(9.0)\end{array}$ & 0.14 & $159.0(5.0)$ & $\begin{array}{l}158.0 \\
(5.0)\end{array}$ & 0.45 & $158.0(8.0)$ & $\begin{array}{l}158.0 \\
(28.0)\end{array}$ & 0.94 \\
\hline \multicolumn{13}{|l|}{$\mathrm{BMI}$} \\
\hline Case & $28.0(8.0)^{c}$ & $\begin{array}{l}28.0 \\
(17.0)\end{array}$ & 0.31 & $29.0(7.0)$ & $29.0(6.0)$ & 0.99 & $29.0(6.0)$ & $30.0(5.0)$ & 0.12 & $28.0(8.0)$ & $29.0(7.0)$ & 0.56 \\
\hline Control & $28.0(6.0)$ & $27.0(6.0)$ & 0.64 & $27.0(4.0)$ & $29.0(6.0)$ & 0.34 & $28.0(5.0)$ & $28.0(4.0)$ & 0.96 & $28.0(6.0)$ & $27.0(9.0)$ & 0.73 \\
\hline \multicolumn{13}{|l|}{ Energy intake } \\
\hline Case & $\begin{array}{l}2167.0 \\
(635.0)^{c}\end{array}$ & $\begin{array}{l}3210.0 \\
(470.0)\end{array}$ & $<0.001$ & $\begin{array}{l}2558.0 \\
(921.0)\end{array}$ & $\begin{array}{l}2764.0 \\
(925.09)\end{array}$ & 0.17 & $\begin{array}{l}2200.0 \\
(614.0)\end{array}$ & $\begin{array}{l}2914.0 \\
(951.0)\end{array}$ & $<0.001$ & $\begin{array}{l}2012.0 \\
(320.0)\end{array}$ & $\begin{array}{l}2778.0 \\
(803.0)\end{array}$ & $<0.001$ \\
\hline Control & $\begin{array}{l}2177.0 \\
(631.0)\end{array}$ & $\begin{array}{l}3411.0 \\
(1412.0)\end{array}$ & $<0.001$ & $\begin{array}{l}2541.0 \\
(1021.0)\end{array}$ & $\begin{array}{l}2622.0 \\
(1069.0)\end{array}$ & 0.95 & $\begin{array}{l}2355.0 \\
(784.0)\end{array}$ & $\begin{array}{l}3307.0 \\
(1245.0)\end{array}$ & $<0.001$ & $\begin{array}{l}1962.0 \\
(377.0)\end{array}$ & $\begin{array}{l}3199.0 \\
(1616.0)\end{array}$ & $<0.001$ \\
\hline \multicolumn{13}{|l|}{ Physical activity score } \\
\hline Case & $31.0(5.0)^{c}$ & $33.0(8.0)$ & 0.13 & $32.0(5.0)$ & $33.0(6.0)$ & 0.10 & $30.0(7.0)$ & $33.0(6.0)$ & 0.08 & $32.0(7.0)$ & $32.0(5.0)$ & 0.95 \\
\hline Control & $31.0(5.0)$ & $32.0(7.0)$ & 0.86 & $31.0(5.0)$ & $33.0(6.0)$ & 0.26 & $31.095 .0)$ & $33.0(6.0)$ & 0.03 & $32.0(5.0)$ & $32.0(5.0)$ & 0.59 \\
\hline \multicolumn{13}{|l|}{ Menarche age } \\
\hline Case & $14.0(1.0)^{c}$ & $14.0(2.0)$ & 0.58 & $13.0(2.0)$ & $13.0(2.0)$ & 0.39 & $14.0(1.0)$ & $13.0(2.0)$ & 0.74 & $14.0(2.0)$ & $14.0(2.0)$ & 0.71 \\
\hline Control & $13.0(1.0)$ & $14.0(2.0)$ & 0.02 & $13.0(1.0)$ & $14.0(2.0)$ & 0.02 & $13.0(2.0)$ & $14.0(2.0)$ & 0.17 & $13.0(1.0)$ & $14.0(1.0)$ & 0.82 \\
\hline \multicolumn{13}{|l|}{ Menopause status } \\
\hline Case status & & & 0.004 & & & $<0.001$ & & & $<0.001$ & & & \\
\hline Premenopause & $29(47.5)^{d}$ & $6(35)$ & & $19(49)$ & $13(54)$ & & $21(48)$ & $11(42)$ & & $9(46)$ & $15(50)$ & $<0.001$ \\
\hline Postmenopause & $32(52.5)$ & $11(65)$ & & $20(51)$ & $11(36)$ & & $23(52)$ & $15(58)$ & & $22(54)$ & $15(50)$ & \\
\hline Control status & & & 0.06 & & & $<0.001$ & & & 0.01 & & & $<0.001$ \\
\hline Premenopause & $52(58)$ & $19(50)$ & & $34(68)$ & $30(53.5)$ & & $28(52)$ & $17(37)$ & & $27(51)$ & $30(56)$ & \\
\hline Postmenopause & $38(42)$ & $19(50)$ & & $16(32)$ & $26(46.5)$ & & $25(48)$ & $29(63)$ & & $26(49)$ & $23(44)$ & \\
\hline
\end{tabular}

${ }^{a}$ Dixon's DASH index scores were grouped into 4 categories $[\leq 1(n=151), 2(n=101), 3(n=94)$, and $\geq 4(n=55)$ points] because of a limited range of values. DASH, Dietary Approaches to Stop Hypertension

${ }^{\mathrm{b}}$ Mean $\pm \mathrm{SE}$ (all such values)

${ }^{c}$ Median (IQR) (all such values)

${ }^{\mathrm{d}}$ Number (Percent) (all such values) 
Table 3 Spearman's correlation coefficients in summary scores for 4 DASH diet indexes ${ }^{a}$

\begin{tabular}{lllll}
\hline & Dixon's DASH index & Mellen's DASH index & Fung's DASH index & Günther's DASH index \\
\hline Dixon's DASH index & 1.00 & 0.27 & 0.69 & 0.58 \\
Mellen's DASH index & 0.27 & 1.00 & 0.29 & 0.07 \\
Fung's DASH index & 0.69 & 0.29 & 1.00 & 0.61 \\
Günther's DASH index & 0.58 & 0.07 & 0.61 & 1.00 \\
\hline
\end{tabular}

${ }^{\mathrm{a}} P<0.0001$

weakest correlation was between Gunther's and Mellen's DASH indexes $(r=0.07)$.

The ORs and their 95\% CI for total DASH scores and breast cancer risk are shown in Table 4. After controlling for potential confounders, women in the highest quintiles of the Mellen's and Günther's scores had 50, and $52 \%$ lower odds of breast cancer than those in the lowest quintiles respectively (Mellen's OR: 0.50; 95\% CI: 0.62-0.97; P-trend: 0.02;Günther's OR: 0.48; 95\% CI: 0.25-0.93, P-trend: 0.05). However, no significant associations were found between Dixon's and Fung's DASH score and breast cancer risk.

Further stratification by menopausal status revealed that Dixon's DASH diet index, Fung's DASH diet index, and Günther's DASH diet index were not significantly associated with breast cancer risk between premenopausal and postmenopausal women. However, risk estimates were significantly reduced for breast cancer in postmenopausal women with higher scores on Mellen's DASH index (Multivariate OR: 0.24; 95\% CI: 0.08-0.68; P-trend: 0.04).

Table 5 shows the multivariate adjusted ORs and 95\% Confidence Intervals (CIs) for breast cancer risk bycomponent analyses (mutual adjustment). Each individual component was examined solely, with the total index score minus the relevant component controlled for. Among components in which higher intakes captured greater scores, the following were significantly related to reduced risk of breast cancer: total fruits, total grains and total dairy product with Dixon's DASH index, potassium with Mellen's DASH index, total fruit, vegetables (without potatoes), and low-fat dairy products with Fung's DASH index, and total vegetables, total dairy products, and low-fat dairy products with the Günther's DASH index.

\section{Discussion}

To the best of our knowledge, our study is the first observational study that epidemiologically examined the association between 4 DASH diet indexes and breast cancer risk. In present case-control study, we found that a greater adherence to 2 of the 4 DASH indexes (Mellen's and Günther's indexes) was associated with markedly decreased risk of breast cancer in Iranian women. After stratified by menopausal status, only Mellen's
DASH index was linked to reduced risk of breast cancer, among postmenopausal women. The available evidence linking the DASH diet to breast cancer is limited. Fung et al. reported that the whole DASH was significantly associated with a lower risk of ER-breast cancer in postmenopausal women [10]. Recently, Soltani et al. also revealed that in Iranian women the highest quartile of the DASH diet score had 85\% lower odds of breast cancer than women in the bottom quartile. Stratified analysis showed such association in postmenopausal women, but not in premenopausal women [23].

The results of current study suggest that the main effective components of the DASH diet, which can protect against breast cancer, may exist in almost all indexes. On the other hand, the lack of an association between Dixon's and Fung's DASH scores and breast cancer in our research demonstrates that differing in composition of the indexes (some indexes emphasize on food choices; however, the other may be nutrient-based or caloriebased) and the scoring procedures may affect the results. Dixon and Günther indexes use certain cutoffs and Fung index applies rankings of intakes whereas Mellen's index includes a density-based method (ie, intakes are evaluated relative to total calorie). Furthermore, Dixon's and Mellen's indexes directly assess the saturated fat intake while both indexes developed by Fung and Günther estimate the intake of saturated fat indirectly through consumption of saturated fat rich foods [11, 24-26]. Finally, it is important to understand the inherent difference of DASH index formulation. In Dixon's method, meat and meat equivalent consumption have been considered. However, Fung's index notices intake of red and processed meat, and in Günther's index intake of meat, poultry, fish, and eggs is important [11, 24, 25].

In a cohort study by Miller et al., men with the highest scores on all 4 of the indexes and women with the highest scores on Mellen's, Fung's, and Günther's indexes had significant reduced risk of colorectal cancer [7]. The Fung's index consists of 8 components including 7 food groups and one nutrient (sodium) [10]. This index has been used frequently in studies which investigated the association between DASH dietary pattern and diseases $[10,30]$. Unlike our results, Hirko et al. reported that a significant reduced risk of human epidermal growth factor 2 positive breast cancer was observed among women 
Table 4 Multivariable adjusted $\mathrm{ORs}^{\mathrm{a}}(95 \% \mathrm{Cls})$ for breast cancer in women by category or quintiles of DASH diet index scores

\begin{tabular}{|c|c|c|c|c|c|c|}
\hline \multirow[t]{2}{*}{ DASH index } & \multicolumn{5}{|c|}{ Quintiles of DASH index } & \multirow[t]{2}{*}{ P- tre } \\
\hline & Q1 & Q2 & Q3 & Q4 & Q5 & \\
\hline \multicolumn{7}{|l|}{ Dixon's DASH index } \\
\hline \multicolumn{7}{|l|}{ All women } \\
\hline Cases/controls & $61 / 90$ & $29 / 72$ & $27 / 66$ & $17 / 38$ & - & \\
\hline Crude OR & 1.00 (referent) & $0.59(0.34-1.02)$ & $0.59(0.34-1.03)$ & $0.66(0.34-1.27)$ & & 0.08 \\
\hline Multivariate OR & 1.00 (referent) & $0.79(0.42-1.45)$ & $0.80(0.43-1.52)$ & $0.94(0.42-2.13)$ & - & 0.71 \\
\hline \multicolumn{7}{|l|}{ Premenopause } \\
\hline Case/control & $29 / 52$ & $14 / 43$ & $13 / 38$ & $6 / 19$ & - & \\
\hline Multivariate OR & 1.00 (referent) & $0.81(0.33-1.97)$ & $0.85(0.35-2.04)$ & $0.91(0.28-2.96)$ & - & 0.79 \\
\hline \multicolumn{7}{|l|}{ Postmenopause } \\
\hline Cases/controls & $32 / 38$ & $15 / 29$ & $14 / 28$ & $11 / 19$ & - & \\
\hline Multivariate OR & 1.00 (referent) & $0.67(0.27-1.66)$ & $0.56(0.21-1.54)$ & $0.70(0.21-2.29)$ & - & 0.39 \\
\hline \multicolumn{7}{|l|}{ Mellen's DASH index } \\
\hline \multicolumn{7}{|l|}{ All women } \\
\hline Cases/controls & $39 / 50$ & $38 / 75$ & $19 / 47$ & $14 / 38$ & $24 / 56$ & \\
\hline Crude OR & 1.00 (referent) & $0.66(0.37-1.17)$ & $0.52(0.26-1.04)$ & $0.48(0.23-1.01)$ & $0.5690 .29-1.05)$ & 0.04 \\
\hline Multivariate $\mathrm{OR}$ & 1.00 (referent) & $0.61(0.34-1.09)$ & $0.48(0.24-0.96)$ & $0.43(0.20-0.92)$ & $0.50(0.62-0.97)$ & 0.02 \\
\hline \multicolumn{7}{|l|}{ Premenopause } \\
\hline Cases/controls & $19 / 34$ & $18 / 36$ & $8 / 29$ & $4 / 23$ & $13 / 30$ & \\
\hline Multivariate $O R$ & 1.00 (referent) & $0.84(0.37-1.91)$ & $0.48(0.18-1.26)$ & $0.30(0.09-1.02)$ & $0.78(0.32-1.87)$ & 0.22 \\
\hline \multicolumn{7}{|l|}{ Postmenopause } \\
\hline Cases/controls & $20 / 16$ & $20 / 39$ & $11 / 18$ & $10 / 15$ & $11 / 26$ & \\
\hline Multivariate OR & 1.00 (referent) & $0.26(0.10-0.67)$ & $0.30(0.10-0.67)$ & $0.34(0.11-1.05)$ & $0.24(0.08-0.68)$ & 0.04 \\
\hline \multicolumn{7}{|l|}{ Fung's DASH index } \\
\hline \multicolumn{7}{|l|}{ All women } \\
\hline Cases/controls & $44 / 53$ & $19 / 70$ & $17 / 53$ & $28 / 45$ & $26 / 46$ & \\
\hline Crude OR & 1.00 (referent) & $0.32(0.17-0.62)$ & $0.38(0.19-0.76)$ & $0.74(0.40-1.39)$ & $0.68(0.36-1.27)$ & 0.71 \\
\hline Multivariate $O R$ & 1.00 (referent) & $0.31(0.16-0.62)$ & $0.40(0.19-0.83)$ & $0.74(0.38-1.44)$ & $0.49(0.25-0.98)$ & 0.28 \\
\hline \multicolumn{7}{|l|}{ Premenopause } \\
\hline Cases/controls & $21 / 28$ & $9 / 44$ & $7 / 36$ & $14 / 27$ & $11 / 17$ & \\
\hline Multivariate $O R$ & 1.00 (referent) & $0.27(0.11-0.69)$ & $0.25(0.08-0.72)$ & $0.68(0.27-1.67)$ & $0.74(0.27-2.03)$ & 0.73 \\
\hline \multicolumn{7}{|l|}{ Postmenopause } \\
\hline Cases/controls & $23 / 25$ & $10 / 26$ & $10 / 16$ & $14 / 18$ & $15 / 29$ & \\
\hline Multivariate $O R$ & 1.00 (referent) & $0.38(0.13-1.05)$ & $0.62(0.21-1.81)$ & $0.50(0.17-1.41)$ & $0.36(0.13-0.94)$ & 0.07 \\
\hline \multicolumn{7}{|c|}{ Günther's DASH index } \\
\hline \multicolumn{7}{|l|}{ All women } \\
\hline Cases/controls & $41 / 53$ & $25 / 53$ & $17 / 54$ & $21 / 53$ & $30 / 53$ & \\
\hline Crude OR & 1.00 (referent) & $0.51(0.27-0.97)$ & $0.26(0.12-0.56)$ & $0.86(0.48-1.54)$ & $0.52(0.27-0.99)$ & 0.22 \\
\hline Multivariate $O R$ & 1.00 (referent) & $0.41(0.21-0.82)$ & $0.36(0.17-0.75)$ & $0.48(0.24-0.95)$ & $0.48(0.25-0.93)$ & 0.05 \\
\hline \multicolumn{7}{|l|}{ Premenopause } \\
\hline Cases/controls & $19 / 27$ & $13 / 31$ & $8 / 36$ & $7 / 28$ & $15 / 30$ & \\
\hline Multivariate OR & 1.00 (referent) & $0.33(1.25-0.91)$ & $0.26(0.09-0.79)$ & $0.37(0.12-1.12)$ & $0.57(0.22-1.5)$ & 0.37 \\
\hline \multicolumn{7}{|l|}{ Postmenopause } \\
\hline Cases/controls & $22 / 26$ & $12 / 22$ & $9 / 18$ & $14 / 25$ & $15 / 23$ & \\
\hline
\end{tabular}


Table 4 Multivariable adjusted $\mathrm{ORs}^{\mathrm{a}}(95 \% \mathrm{Cls})$ for breast cancer in women by category or quintiles of DASH diet index scores (Continued)

\begin{tabular}{cllllll}
\hline DASH index & \multicolumn{4}{l}{ Quintiles of DASH index } & Q2 & Q4 trend \\
\cline { 2 - 5 } & Q1 & Q2 & Q3 & Q5 & $0.50(0.18-1.34)$ \\
\hline Multivariate OR & 1.00 (referent) & $0.42(0.15-1.16)$ & $0.43(0.14-1.29)$ & $0.52(0.19-1.37)$ & 0.21 \\
\hline
\end{tabular}

Dixon's DASH index scores were grouped into 4 categories $(\leq 1,2,3$, and $\geq 4$ points) because of a limited range of values (total score range is $0-9)$.OR: odds ratio, 95\% Cl: $95 \%$ confidence interval. Statistically significant $P$-values are reported in bold, ${ }^{*} p \leq 0.05$ considered as significant

${ }^{a}$ Adjusted for age, BMI, energy intake, physical activity, age at first live birth, vitamin D supplements and family history of cancer

Table 5 Multivariable-adjusted ORs ( $95 \%$ Cls) for breast cancer for highest compared with lowest categories or quintiles of DASH individual component scores for each index in women ${ }^{\text {a }}$

\begin{tabular}{|c|c|c|c|c|}
\hline & $\begin{array}{l}\text { Dixon's DASH } \\
\text { index }\end{array}$ & $\begin{array}{l}\text { Mellen's DASH } \\
\text { index }^{\mathbf{b}}\end{array}$ & $\begin{array}{l}\text { Fung's DASH } \\
\text { index }\end{array}$ & $\begin{array}{l}\text { Günther's DASH } \\
\text { index }\end{array}$ \\
\hline \multicolumn{5}{|c|}{$\begin{array}{l}\text { Dietary components for which greater intakes receive higher } \\
\text { score }\end{array}$} \\
\hline Total fruit & $0.68(0.44-1.04)$ & - & $0.42(0.21-0.84)$ & $0.95(0.84-1.08)$ \\
\hline Total vegetables & $0.50(0.33-0.77)$ & - & - & $0.87(80-0.96)$ \\
\hline Vegetables without potatoes & - & - & $0.49(0.25-0.98)$ & - \\
\hline Total grains & - & - & - & $1.03(0.81-1.31)$ \\
\hline Whole grains & $0.51(0.36-0.86)$ & - & $1.83(0.89-3.73)$ & - \\
\hline High-fiber grains & - & - & - & $1.15(0.73-1.82)$ \\
\hline Total dairy products & $0.54(0.35-0.83)$ & - & - & $0.83(0.70-0.99)$ \\
\hline Low-fat dairy products & - & - & $0.46(0.23-0.92)$ & $0.79(0.63-0.99)$ \\
\hline Nuts, seeds, legumes & $1.36(0.84-2.19)$ & - & $0.96(0.46-2.00)$ & $1.04(0.94-1.51)$ \\
\hline Protein & - & $1.49(0.50-4.39)$ & - & - \\
\hline Fiber & - & $0.69(0.34-1.38)$ & - & - \\
\hline Magnesium & - & $0.83(0.52-1.32)$ & - & - \\
\hline Calcium & - & $0.80(0.50-1.29)$ & - & - \\
\hline Potassium & - & $0.61(0.40-0.94)$ & - & - \\
\hline \multicolumn{5}{|c|}{$\begin{array}{l}\text { Dietary components for which lower intakes receive higher } \\
\text { scores }\end{array}$} \\
\hline Meat/meat equivalents & $1.10(0.37-3.25)$ & - & - & - \\
\hline Meat, poultry, fish, eggs & - & - & - & $0.96(0.82-1.14)$ \\
\hline Red and processed meat & - & - & $2.03(1.00-4.14)$ & - \\
\hline Sugar-sweetened beverages & - & - & $0.75(0.42-1.34)$ & - \\
\hline Sweets & - & - & - & $1.01(096-1.07)$ \\
\hline Added sugar & $0.88(0.57-1.36)$ & - & - & - \\
\hline Fats, oils & - & - & - & $1.03(098-1.05)$ \\
\hline Total fat & - & $0.94(0.59-1.51)$ & - & - \\
\hline Saturated fat & $1.01(0.99-1.06)$ & $071(0.46-1.08)$ & - & - \\
\hline Cholesterol & - & $0.87(0.55-1.37)$ & - & - \\
\hline Sodium & - & $1.16) 0.63-2.12)$ & $1.49(0.76-2.92)$ & - \\
\hline
\end{tabular}

${ }^{a}$ Multivariable adjusted ORs (95\% Cls) were conducted for each component with adjustment for the total DASH score without the respective component in addition to age, BMI, energy intake, physical activity, age at first live birth, vitamin D supplements and family history of cancer

${ }^{\mathrm{b}}$ Meeting the recommendation (1 point) compared with not meeting the recommendation ( 0 points)

'Quintile 5 compared with quintile 
in 5th vs. 1st quintile of DASH scores based on Fung's index [30]. However, Fung's score had no significant association with other molecular subtypes of breast cancer in this study [30]. Similar significant inverse association between a high DASH score based on Fung's index and ER-breast cancer but not of ER+ breast cancer, was reported in a study by Fung et al. [10].

In previous studies on dietary patterns and breast cancer risk in Iranian women, a 'healthy' dietary pattern characterized by the consumption of vegetables, fruits, low-fat dairy products, legumes, olive and vegetable oils, fish, condiments, organ meat, poultry, soya and whole grains was inversely related to breast cancer risk [21]. Moreover, the results of another study by Heidari et al. showed significant increase in breast cancer risk in women in the highest category of the unhealthy dietary pattern (OR: 2.21; 95\%CI: 1.04, 4.690; P-trend $=0.009$ ) [30]. The mentioned study also showed that after stratifying by menopausal status, the association between breast cancer risk and unhealthy dietary pattern was statistically significant only among post-menopausal women (OR: 3.56; 95\%CI: 1.16, 10.95; P-trend =0.008) [28]. In our study, component analysis revealed that in overall, greater intake of fruits, total vegetables, vegetables without potatoes, grains, total dairy product, low fat dairy products and potassium was significantly associated with reduced risk of breast cancer. Fruits and vegetables are rich sources of antioxidants, vitamins, minerals and fiber which have been shown to play a protective role against breast cancer [10, 31].

Comparing 4 DASH diet indexes in the same study for the same outcome is the main strength of our study. In addition, only recently diagnosed women with breast cancer (within the past 6 months) were enrolled in this study. Therefore, alteration in the diet by cases due to cancer diagnosis is less possible. The high participation rate of the study subjects and adjusting the analysis for confounding variables were the other strength of the study. Where economic resources are severely limited, food consumption is strongly correlated to income so that even little income differences are directly reflected in diet. Thus, studies in developing countries can offer unique opportunities to investigate the association between diet and cancer (due to large between person variation) [32]. Moreover, dietary patterns are likely to vary according to geographic region, socio-economic status, cultural practices, and food preferences and availability [28]. Especially, dietary intake of the Middle-Eastern population has its own unique characteristics, being recognized by higher consumption of refined grains (white rice and bread) and hydrogenated fats and a higher percentage of energy from carbohydrates [28].

On the other hand, our study has some limitations. First, recall bias is possible due to the hospital-based case-control design of study. In case-control studies, cases may recall their previous diet differently in the context of their cancer diagnosis and this can affect the associations (overestimation). Second, the possibility of selection bias cannot be avoided in retrospective case-control studies. In the present study, the probability of selection bias was minimized by high participation rates and by selecting hospital controls from patients whose admission diagnosis was unrelated to alcohol intake, tobacco smoking, and diet-related diseases (limiting share exposure). Lack of precision of results due to small sample size is another limitation of our study. Moreover, although we used a validated food-frequency questionnaire for assessing the dietary intake, measurement errors that might led to underestimation or even over estimation of associations were inevitable [29]. Finally, breast cancer is a hormonesensitive cancer and evidence indicates that dietary pattern may have an impact on some subtypes of breast cancer and no effect on others. For example, two prospective cohort studies showed that DASH scores were inversely associated with ER- breast cancer $[5,10]$. Therefore, it was better to stratify the results by hormone receptor status. However, we didn't collect the information about the cancer subtype of our patients. Additional well-designed studies without these limitations are needed to elucidate the role of various aspects of 4 DASH diet indexes in prediction of breast cancer risk and find a standardized DASH diet index in these patients.

\section{Conclusion}

Overall, we demonstrated that 2 of 4 DASH diet indexes (Mellen's and Günther's) reduced breast cancer risk in women. Nevertheless, minor differences in scoring method of these indexes can affect the results which should be taken into consideration in future research.

\section{Abbreviations \\ BMI: Body mass index; Cls: Confidence Intervals; DASH: Dietary Approaches to Stop Hypertension; ER: Estrogen receptor; FFQ: Food frequency} questionnaire; HRT: Hormone replacement therapy; OR: Odds ratio

\section{Acknowledgments \\ The authors gratefully acknowledge all the participants for their assistance.}

\section{Authors' contributions}

$\mathrm{ZH}$ and EM participated in the conception, design, drafting and final approval of the manuscript. FS contributed to conception, analysis and interpretation of data, drafting and final approval of the manuscript.VA carried out the study and participated in drafting and final approval of the manuscript. SJ and AR participated in data acquisition, drafting and final approval of the manuscript. BH contributed to conception, design, revising the manuscript critically for important intellectual content and final approval of manuscript. MA contributed to manuscript editing, and English editing of our manuscript. She also provided critical feedback for revising the manuscript. The authors read and approved the final manuscript.

\section{Funding}

This study was funded by the National Nutrition and Food Technology Research Institute, Shahid Beheshti University of Medical Sciences, Tehran, Iran. 


\section{Availability of data and materials}

The data and materials are available from the corresponding author on reasonable request.

\section{Ethics approval and consent to participate}

The ethics board of the National Nutrition and Food Technology Research Institute of Shahid Beheshti University of Medical Science approved the study protocol and a written informed consent was obtained from all participants before enrolment in the study.

\section{Consent for publication}

Not applicable.

\section{Competing interests}

The authors declare that they have no competing interests.

\section{Author details}

'Department of Community Nutrition, Faculty of Nutrition Sciences and Food Technology, National Nutrition and Food Technology Research Institute, Shahid Beheshti University of Medical Sciences, Tehran, Iran. ${ }^{2}$ Department of Nutrition, Khalkhal University of Medical Sciences, Khalkhal, Iran. ${ }^{3}$ Department of Basic Medical Sciences, Faculty of Nutrition Sciences and Food Technology, National Nutrition and Food Technology Research Institute, ShahidBeheshti University of Medical Sciences, No 46, Hafezi Street, Farahzadi Boulevard, Sharak Ghods, P.O. Box: 1981619573, Tehran, Iran. ${ }^{4}$ Department of Oncology, Shahid Madani Hospital, Alborz University of Medical Science, Karaj, Iran.

Received: 23 October 2019 Accepted: 23 July 2020

Published online: 29 July 2020

\section{References}

1. Tao Z, Shi A, Lu C, Song T, Zhang Z, Zhao J. Breast Cancer: epidemiology and etiology. Cell Biochem Biophys. 2015;72(2):333-8.

2. Shulman LN, Willett W, Sievers A, Knaul FM. Breast cancer in developing countries: opportunities for improved survival. J Oncol. 2010;2010:595167.

3. Farhood B, Geraily G, Alizadeh A. Incidence and mortality of various cancers in Iran and compare to other countries: a review article. Iran J Public Health. 2018:47(3):309-16.

4. Lammert J, Grill S, Kiechle M. Modifiable lifestyle factors: opportunities for (hereditary) breast Cancer prevention - a narrative review. Breast Care (Basel). 2018;13(2):109-14.

5. Petimar J, Park YM, Smith-Warner SA, Fung TT, Sandler DP. Dietary index scores and invasive breast cancer risk among women with a family history of breast cancer. Am J Clin Nutr. 2019;109(5):1393-401.

6. Baglietto L, Krishnan K, Severi G, Hodge A, Brinkman M, English DR. Dietary patterns and risk of breast cancer. Br J Cancer. 2011;104(3):524-31.

7. Miller PE, Cross AJ, Subar AF, Krebs-Smith SM, Park Y, Powell-Wiley T. Comparison of 4 established DASH diet indexes: examining associations of index scores and colorectal cancer. Am J Clin Nutr. 2013;98(3):794-803.

8. Catsburg C, Kim RS, Kirsh VA, Soskolne CL, Kreiger N, Rohan TE. Dietary patterns and breast cancer risk: a study in 2 cohorts. Am J Clin Nutr. 2015; 101(4):817-23

9. Izano MA, Fung TT, Chiuve SS, Hu FB, Holmes MD. Are diet quality scores after breast cancer diagnosis associated with improved breast cancer survival? Nutr Cancer. 2013;65(6):820-6.

10. Fung TT, Hu FB, Hankinson SE, Willett WC, Holmes MD. Low-carbohydrate diets, dietary approaches to stop hypertension-style diets, and the risk of postmenopausal breast cancer. Am J Epidemiol. 2011;174(6):652-60.

11. Dixon LB, Subar AF, Peters U, Weissfeld JL, Bresalier RS, Risch A, et al. Adherence to the USDA food guide, DASH eating plan, and Mediterranean dietary pattern reduces risk of colorectal adenoma. J Nutr. 2007;137(11): 2443-50.

12. Fung TT, Hu FB, Wu K, Chiuve SE, Fuchs CS, Giovannucci E. The Mediterranean and dietary approaches to stop hypertension (DASH) diets and colorectal cancer. Am J Clin Nutr. 2010;92(6):1429-35.

13. Adebamowo CA, Hu FB, Cho E, Spiegelman D, Holmes MD, Willett WC. Dietary patterns and the risk of breast cancer. Ann Epidemiol. 2005;15:78995.
14. Fung $T$, Hu FB, Holmes MD, Rosner BA, Hunter DJ, Colditz GA, et al. Dietary patterns and the risk of postmenopausal breast cancer. Int J Cancer. 2005: 116:116-21.

15. Mannisto S, Dixon LB, Balder HF, Virtanen MJ, Krogh V, Khani BR, et al. Dietary patterns and breast cancer risk: results from three cohort studies in the DIETSCAN project. Cancer Causes Control. 2005;16:725-33.

16. Schulz M, Hoffmann K, Weikert C, Nothlings U, Schulze MB, Boeing H. Identification of a dietary pattern characterized by high-fat food choices associated with increased risk of breast cancer: the European prospective investigation into Cancer and nutrition [EPIC]-Potsdam study. Br J Nutr. 2008;100:942-6.

17. Sieri S, Krogh V, Pala V, Muti P, Micheli A, Evangelista A, et al. Dietary patterns and risk of breast cancer in the ORDET cohort. Cancer Epidemiol Biomark Prev. 2004;13:567-72.

18. Cui X, Dai Q, Tseng M, Shu XO, Gao YT, Zheng W. Dietary patterns and breast cancer risk in the shanghai breast cancer study. Cancer Epidemiol Biomark Prev. 2007;16:1443-8.

19. Edefonti V, Decarli A, La Vecchia C, Bosetti C, Randi G, Franceschi S, et al. Nutrient dietary patterns and the risk of breast and ovarian cancers. Int J Cancer. 2008;122:609-13.

20. Franceschi S, Favero A, La Vecchia C, Negri E, Dal Maso L, Salvini S, et al. Influence of food groups and food diversity on breast cancer risk in Italy. Int J Cancer. 1995;63:785-9.

21. Karimi Z, Jessri M, Houshiar-Rad A, Mirzaei HR, Rashidkhani B. Dietary patterns and breast cancer risk among women. Public Health Nutr. 2014;17: 1098-106.

22. Hirose K, Matsuo K, Iwata H, Tajima K. Dietary patterns and the risk of breast cancer in Japanese women. Cancer Sci. 2007;98:1431-8.

23. Soltani S, Benisi-Kohansal S, Azadbakht L, Esmaillzadeh A. Association between adherence to "dietary approaches to stop hypertension" eating plan and breast Cancer. Nutr Cancer. 2020:1-9.

24. Fung TT, Chiuve SE, McCullough ML, Rexrode KM, Logroscino G, Hu FB. Adherence to a DASH-style diet and risk of coronary heart disease and stroke in women. Arch Intern Med. 2008;168:713-20.

25. Günther AL, Liese AD, Bell RA, Dabelea D, Lawrence JM, Rodriguez BL, Standiford DA, Mayer-Davis EJ. Association between the dietary approaches to hypertension diet and hypertension in youth with diabetes mellitus. Hypertension. 2009;53:6-12.

26. Mellen PB, Gao SK, Vitolins MZ, Goff DC Jr. Deteriorating dietary habits among adults with hypertension: DASH dietary accordance, NHANES 19881994 and 1999-2004. Arch Intern Med. 2008;168:308-14.

27. Aadahl M, Jørgensen T. Validation of a new self-report instrument for measuring physical activity. Med Sci Sports Exerc. 2003;35:1196-202.

28. Heidari Z, Jalali S, Sedaghat F, Ehteshami M, Rashidkhani B. Dietary patterns and breast cancer risk among Iranian women: a case-control study. Eur J Obstet Gynecol Reprod Biol. 2018;230:73-8.

29. Asghari G, Rezazadeh A, Hosseini-Esfahani F, Mehrabi Y, Mirmiran P, Azizi F. Reliability, comparative validity and stability of dietary patterns derived from an FFQ in the Tehran lipid and glucose study. Br J Nutr. 2012;108(06):110917.

30. Hirko KA, Willett WC, Hankinson SE, Rosner BA, Beck AH, Tamimi RM, et al. Healthy dietary patterns and risk of breast cancer by molecular subtype. Breast Cancer Res Treat. 2016;155(3):579-88.

31. Masala G, Assedi M, Bendinelli B, Ermini I, Sieri S, Grioni S, et al. Fruit and vegetables consumption and breast cancer risk: the EPIC Italy study. Breast Cancer Res Treat. 2012;132(3):1127-36.

32. Willett $W$, et al. Nutritional epidemiology. 2nd ed. New York: Oxford University Press; 1998.

\section{Publisher's Note}

Springer Nature remains neutral with regard to jurisdictional claims in published maps and institutional affiliations. 